\title{
What is the Social in Social Media?
}

\section{Geert Lovink}

Headlines: 'Next time you're hiring, forget personality tests, just check out the applicant's Facebook profile instead';

'Stephanie Watanabe spent nearly four hours Thursday night unfriending about 700 of her Facebook friends - and she isn't done yet'; 'Facebook apology or jail time: Ohio man gets to choose'; 'Study: Facebook users getting less friendly'; 'Women tend to have stronger feelings regarding who has access to their personal information' (Mary Madden); 'All dressed up and no place to go' (WSJ); 'I'm making more of an effort to be social these days, because I don't want to be alone, and I want to meet people' (Cindy Sherman); '30 percent posted updates that met the American Psychiatric Association's criteria for a symptom of depression, reporting feelings of worthlessness or hopelessness, insomnia or sleeping too much, and difficulty concentrating'; 'Control your patients: "Do you hire someone in the clinic to look at Facebook all day?” Dr. Moreno asked. "That's not practical and borders on creepy."; 'Hunt for Berlin police officer pictured giving Nazi salute on Facebook'; '15-year-old takes to Facebook to curse and complain about her parents. The disgusted father later blasts her laptop with a gun.'

The use of the word 'social' in the context of information technology dates back to the very beginnings of cybernetics. It later pops up again in the 1980s' context of 'groupware'. The materialist school of German media theorist Friedrich Kittler has dismissed the use of the word of 'social' as irrelevant fluff (what computers do is calculate, they do not interfere in human relations, stop projecting our mundane all-toohuman desires onto electronic circuits and so on). Holistic 
hippies of the Wired school on the other hand have ignored this cynical machine knowledge from Old Europe with a positive, humanistic view that emphasises computers as tools for personal liberation and it was Steve Jobs at Apple who turned this mentality into a design and marketing machine. Computers are not made for engineers. From the beginning the 'Californian' individualistic emphasis on cool interface design and usability has been matched with an interest in the community aspect of computer networking. Before the 'dotcom' venture capital takeover of the field in the second half of the 1990 , progressive computing was primarily seen as a tool for collaboration between two or more people.

In his unpublished essay 'How computer networks became social', Sydney media theorist Chris Chesher maps out the historical development from sociometry and social network analysis (with roots are going back to the 1930s), an 'offline' science that studies the dynamics of human networks to Granowetter's theory of the strengths of weak links in 1973, Castells' Network Society (1996) and the current mapping efforts of the techno-scientists that gather under the Actor Network Theory (ANT) umbrella. ${ }^{1}$ The conceptual leap that is relevant here is the move from groups, lists, forums and communities to emphasise empowering loosely connected individuals in networks, a shift that happened throughout the neoliberal 1990s, facilitated by growing computing power, growth in storage capacity and internet bandwidth and easier interfaces on smaller and smaller (mobile) devices. This is where we enter the Empire of the Social. It also needs to be said that 'the social' could only become technical, and become so successful, after the fall of the Berlin Wall in 1989 when state communism no longer posed a (military) threat to free-market capitalism. Computers have always been hybrids of the social and the post-human. From the very being of their industrial life as giant calculators the linking up of different units was seen as a possibility and necessity. As early as 1953, two computers in different locations were able to 'talk' to each other via modems.

If we want to discover an answer to the question 'what does "social" in today's "social media" mean?', a possible starting point could be the notion of the disappearance of the 
social as described by Jean Baudrillard, the French sociologist who theorised the changing role of the subject as consumer. According to Baudrillard at some point the social lost its historical role and imploded into the media. If the social is no longer the once dangerous mix of politicised proletarians, frustrated unemployed and dirty clochards that hang out on the streets, waiting for the next opportunity to revolt under whatever banner, then how do social elements manifest themselves in the digital networked age?

The 'social question' may not have been resolved but at least for decades it felt as if it was neutralised. In the Western post-World War II period, the instrumental knowledge of how to manage the social was seen as a necessity and this reduced the intellectual range to a somewhat closed circle of professional experts that dealt with 'the social'. Now, in the midst of a global economic downturn can we see a renaissance of the social? Is all this talk about the rise of 'social media' just a linguistic coincidence? Can we speak, in the never-ending aftermath of the 2008 financial crisis, of a 'return of the social'? Is there a growing class awareness and, if so, can this spread into the electronic realm? Despite the hardships of unemployment, growing income disparities and Occupy protests, the prospects of a global networked uprising seems unlikely. Protests are successful precisely because they are local, despite their network presence. While 'memes' are travelling at the speed of light and capable of spreading basic concepts, the question remains: How could the separate entities of work, culture, politics and networked communication in a global context be connected in such a way that information (for instance via Twitter) and interpersonal communication (email, Facebook) turn into global events?

We can put such considerations into a larger, strategic context. Do all these neatly administrated contacts and address books at some point spill over and leave the virtual realm, as the popularity of dating sites seems to suggest? Do we only share information, experiences and emotions, or do we also conspire, as 'social swarms', to raid reality in order to create so-called real world events? Will contacts mutate into comrades? It seems that social media solve the organisational problems that the baby boom/suburb generation faced fifty 
years ago: boredom, isolation, depression and desire. How do we come together, right now? Do we unconsciously fear (or long for) the day when our vital infrastructure breaks down and we really need each other? Or should we read the Simulacrum of the Social as an organised agony over the loss of community after the defragmentation of family, marriage, friendship? Why do we assemble these ever growing collections of contacts? Is the Other, relabelled as 'friend', nothing more than a future customer, lifesaver aka business partner? What new forms of social imaginary exist? At what point does the administration of others mutate into something different altogether? Will befriending disappear overnight, like so many new media-related practices that vanished in the digital nirvana?

The container concept 'social media', describing a fuzzy collection of websites from Facebook, Digg, YouTube and Twitter to Wikipedia, is not a nostalgic project aiming to revive the once dangerous potential of 'the social' as angry mob that demands the end of economic inequality. Instead, to remain inside Baudrillard's vocabulary, the social is reanimated as a simulacrum of its own ability to create meaningful and lasting social relations. Roaming around in virtual global networks, we believe we are less and less committed to our roles within traditional communities such as the family, church and neighbourhood. Historical subjects, once defined in terms like citizens or members of a class, carrying certain rights, have been transformed into subjects with agency, dynamic actors called users, customers who complain and prosumers. The social is no longer a reference to society-an insight that troubles us theorists and critics who stick to empirical research which proves that people, despite all their outward behaviour, remain firmly embedded in their traditional, local structures.

The social no longer manifests itself primarily as a class, movement or mob. Neither does it institutionalise itself anymore as happened during the postwar decades of the welfare state. And even the postmodern phase of disintegration and decay seems over. Nowadays the social manifests itself as a network. The networked practices emerge outside the walls of twentieth-century institutions, leading to a 
'corrosion of conformity'. The network is the actual shape of the social. What counts, for instance in politics and business, are the 'social facts' as they present themselves through network analysis and its corresponding data visualisations. The institutional part of life is another matter, a realm that quickly falls behind, becoming a parallel universe. It is tempting to remain positive and portray a synthesis, further down the road, between the formalised power structures inside institutions and the growing influence of the informal networks but there's little evidence of this Third Way approach. The PR-driven belief system that social media will, one day, be integrated is nothing more than New Age optimism. The social, once wonder glue to repair historical damages, can quickly turn into explosive material. A total ban is nearly impossible, even in authoritarian countries. Ignoring social media as background noise also backfires. This is why institutions, from hospitals to universities, hire swarms of temporary consultants to manage social media for them.

Social media fulfil the promise of communication as an exchange instead of forbidding responses that demand replies. Similar to an early writing of Baudrillard's, social media can be understood as 'reciprocal spaces of speech and response' that lure users to say something, anything. ${ }^{2}$ Later on Baudrillard changed his position and no longer believed in the emancipatory aspect of talking back to the media. Restoring the symbolic exchange wasn't enough - and this feature is precisely what social media offer their users as a liberation gesture. What counted for Baudrillard was the superior position of the silent majority.

In their 2012 pamphlet Declaration Michael Hardt and Antonio Negri avoid discussing the larger social dimensions of community, cohesion and society. What they witness is unconscious slavery: 'people sometimes strive for their servitude as if it were their salvation.' It is primarily individual entitlement that interests these theorists in social media, not the social at large. 'Is it possible that in their voluntary communication and expression, in their blogging and social media practices, people are contributing to instead of contesting repressive forces?' For us, the mediatised, work and leisure can no longer be separated. But why don't they express 
interest for the equally obvious observation of productive side of being connected to others?

Hardt and Negri mistakenly reduce social networking to a media question as if internet and smart phones are only used to look up and produce information. Concerning the role of communication they conclude, 'nothing can beat the being together of bodies and the corporeal communication that is the basis of collective political intelligence and action'. ${ }^{3}$ Social links are probably nothing but fluff, a veritable world of sweet sassiness. In this way the true nature of social life online remains out of sight, and thus unscrutinised. Social meets media doesn't have to be sold as some Hegelian synthesis, a direction in which world history necessarily evolves. However, the strong yet abstract concentration of social activity that is already out there is something that needs to be theorised. As such, there is the need for further elucidation of Hardt and Negri's call to refuse mediation: 'We need to make new truths, which can be created by singularities in networks communicating and being there.' We need both networking and encampment. In their version of the social 'we swarm like insects' and act as 'a decentralised multitude of singularities that communicates horizontally'. ${ }^{4}$ But the power structures, and frictions, that emerge from this constellation are yet to be addressed.

The search for the social online will not be found if the project stays with the remains of nineteenth-century European social theory. This is what makes the 'precarious labour' debate about Marx and exploitation inside Facebook so tricky. ${ }^{5}$ What we need to do instead is take the process of socialisation at face value and refrain from well meaning political intentions (for instance to speculate on the possibility of 'Facebook revolutions' in relation to the 2011 Arab Spring and the movements of the squares). The workings of social media are subtle, informal and indirect. How can we understand the social turn in new media, beyond good and evil, as something that is both cold and intimate as Eva Illouz described it in her book Cold Intimacies? ${ }^{6}$ Literature from the media industry and IT tends to shy away from the question posed here. Virtues such as accessibility and usability do not explain what people are looking for 'out there'. There are similar limits to the (professional) 
discourse of trust which also tries to bridge the informal with the legal sphere of rules and regulations.

The 'obliteration of the social' has not led to a disappearance of sociology but indeed downgraded the importance of social theory within critical debates. A 'web sociology' that has freed itself of the real-virtual dichotomies, not limiting its research scope to 'social implications of technology' (such as for example internet addiction) could play a critical role in getting a better understanding of how 'class analysis' and mediatisation are intertwined. As Israeli sociologist Eva Illouz wrote to me in response to this question:

If sociology has traditionally called on us to exert our shrewdness and vigilance in the art of making distinctions (between use value and exchange value; life world and colonisation of the life world, etc.), the challenge that awaits us is to exercise the same vigilance in a social world which consistently defeats these distinctions. ${ }^{7}$

The Amsterdam pioneer of web sociology and editor of SocioSite, Albert Benschop, proposes to overcome the realvirtual distinction all together. In analogy to the Thomas theoreme, a classic in sociology, his slogan is: 'If people define networks as real, they are real in their consequences.' For Benschop, internet is not some 'second-hand world'. The same could be said about the social. There is no second life, with other social rules and conventions. According to Benschop this is why there is, strictly speaking, no additional discipline necessary. ${ }^{8}$ The discussion about the shape of the social relates to all of us and should not be cooked up - and ownedby geeks and startup entrepreneurs only.

The social is not merely the (digital) awareness of the Other, even though the importance of 'direct contact' should not be underestimated. There needs to be actual, real, existing interaction. This is the main difference between old broadcast media and the current social network paradigm. Interpassivity, the concept which points at a perceived growth of the delegation of passions and desires to others (the outsourcing of affect) as discussed for instance by Pfaller, Žižek and van Oenen is a nice but harmless concept in this (interactive) 
context. ${ }^{9}$ To question the current architectures and cultures of use of social media is not motivated by some kind of hidden, oppressed offline romanticist sentiment. Is there something like a justified feeling of overexposure not just to information in general but to others as well? We all need to have a break from the social circus every now and then but who can afford to cut off ties indefinitely? In the online context the social requires our constant involvement in terms of clicking. We need to make the actual link. Machines will not make the vital connection for us, no matter how much we delegate. It is no longer enough to build on your existing social capital. What social media does is algorithmically expand your reach - or that's at least at the promise.

Instead of merely experiencing our personal history as something that we reconcile with and feel the need to overcome (think of family ties, the village or suburb, school and college, church and colleagues from work), the social is seen as something that we are proud of, that we love to represent and show off. Social networking is experienced in terms of an actual potentiality: I could contact this or that person (but I won't). From now on I will indicate what my preferred brand is (even without being asked). The social is the collective ability to imagine the connected subjects as a temporary unity. The power of what it means to connect to many is felt by many. Simulation of the social on websites and in graphs are not so much secondary experiences or representations of something real but are probes into a post-literate world ruled by images.

Martin Heidegger's 'we don't call, we are being called' runs empty here. ${ }^{10} \mathrm{On}$ the net bots will contact you regardless, and the status updates of others, relevant or not, will pass by anyway. The filter failure is real. Once inside the busy flow of social media the 'call to being' comes from software and invites you to reply. This is where the cool and laid-back postmodern indifference as quasi-subversive attitudes comes to an end. It is meaningless not to bother. We are not friends anyway. Why stay on Facebook? Forget Twitter. These are cool statements - but beside the point. The silence of the masses Baudrillard spoke about has been broken. Social media has been a clever trick to get them talking. We have all been reactivated. The obscenity of common opinions and the everyday 
life prostitution of private details is now firmly embedded in software and used by billions of users.

The example Baudrillard used at the time is the opinion poll that undermines 'the authentic existence of the social'. Baudrillard replaced the sad vision of the masses as an alienated entity by an ironic and object-centred one. Nowadays, thirty years deeper into the media era, even this vision has become internalised. In the Facebook age surveys can now be done continuously, without people's direct participation in questionnaires and the like, through data mining. These algorithmic calculations run in the background and measure every single click, touch of the keyboard and use of keywords. For Baudrillard this 'positive absorption into the transparency of the computer' is something worse than alienation. ${ }^{11}$ The public has become a database full of users. The 'evil genius of the social' has no other way to express itself than to go back, to the streets and squares, guided and witnessed by the multitude of viewpoints that tweeting smart-phones and recording digital cameras produce. The subject as user leaves few options other than to troll in the comment section or continue as a lurker. Much in the same way as Baudrillard questioned the outcome of opinion polls as a subtle revenge of the common people on the political/media system, in the same way we should question the objective truth of the so-called big data originating from Google, Twitter and Facebook. Most of the traffic on social media originates from millions of computers talking to each other. An active participation of 10 per cent of the user base is high. They are assisted by an army of dutifully hard-working software bots, the rest are inactive accounts. This is what object-oriented philosophy has yet come to term with: a critique of useless contingency.

The social media system no longer 'plunges us in a state of stupor,' as Baudrillard described the media experience decades ago. Instead, it shows us the way to cooler apps and other products that elegantly make us forget yesterday's flavour of the day. We simply click, tap and drag the platform away, finding something else to distract us. This is how we treat online services: they are deserted and left behind, if possible on abandoned hardware. Within weeks we have forgotten the icon, bookmark or password. We do not have to revolt 
against the new media of the Web 2.0 era, we can just leave them knowing that they will remain out there like the good old HTML ghost towns of the nineties.

Baudrillard thus summed up the situation of the old media: 'This is our destiny, subjected to opinion polls, information, publicity, statistics: constantly confronted with the anticipated statistical verification of our behaviour, absorbed by this permanent refraction of our least movements, we are no longer confronted with our own will.' He discussed the move towards obscenity that is made in the permanent display of one's own preferences (in our case on social media platforms). There is a 'redundancy of the social', a 'continual voyeurism of the group in relation to itself: it must at all times know what it wants ... The social becomes obsessed with itself; through this auto-information, this permanent auto-intoxication.'

The difference between the 1980 os when Baudrillard wrote these theses and the present is the opening up of all aspects of life to the logic of opinion polls. Not only do we have personal opinions about every possible event, idea or product, but these informal judgements are also interesting for the databases and search engines. People start to talk about products by themselves; they no longer need incentives from outside. Twitter goes for the entire spectre of life when it asks 'What's happening?' Everything, even the tiniest info spark provided by the online public is (potentially) relevant, ready to be earmarked as viral and trending, destined to be data-mined and, once stored, ready to be combined with other details. These devices of capture are totally indifferent to the content of what people say - who cares about your views? It's all just data to be mined, recombined and flogged off. That's network relativism. In the end it's all just data, their data. 'Victor, are you still alive?'12 This is not about participation, remembrance and forgetting. What we transmit are the bare signals that we are still alive.

A deconstructivist reading of social media shouldn't aim, once again, to reread the friendship discourse ('from Socrates to Facebook') or take apart the online self. No matter how hard such a task is, theorists should shy away from their built-in 'interpassivity' impulse to call for a break ('book your offline holiday') as this position has played itself out. Instead, 
we need cybernetics 2.0 initiatives such as a follow-up of the original Macy conferences (1946 to 1953) to investigate the cultural logic inside social media, insert self-reflexivity in code and ask what software architectures could be proposed to radically alter the online social experience. We need input from critical humanities and social science that starts a dialogue with computer science on an equal basis. Are 'software studies' initiatives up to such a task? Time will tell. Digital humanities with its one-sided emphasis on data visualisation, working with computer-illiterate humanities scholars as innocent victims, has so far made a bad start in this respect. We do not need more tools; what's required are large research programs that finally put critical theory in the driver's seat, run by technologically informed theorists. The submissive attitude towards the hard sciences and industries in arts and humanities needs to come to a close.

And how can philosophy contribute? The Western male self-disclosing subject no longer needs to be taken apart and contrasted with the liberated cyber-identity aka avatar that roams around the virtual game worlds. Interesting players in the new media game can be found across the globe, from Africa to the obvious players in Brazil, India and the greater China vicinity. For this IT-informed postcolonial theory has yet to be assembled. We should look at today's practices of the social as electronic empathy right in the eyes. How do you shape and administer your online affects? To put it in terms of theory, we need to extend Derrida's questioning of the Western subject to the non-human agency of software (as described by Bruno Latour and his ANT followers). Only then can we get a better understanding of the cultural policy of aggregators, the role of search engines or edit wars inside Wikipedia.

With its emphasis on Big Data we can read the 'renaissance of the social' in the light of sociology as the 'positivist science of society'. As of yet there is no critical school in sight that could help us to properly read the social aura of the citizen as user. The term 'social' has effectively been neutralised in its cynical reduction to data porn. Reborn as a cool concept in the media debate 'the social' manifests itself neither as dissent nor as subcultural. The social organises 
the self as a techno-cultural entity, a special effect of software which real-time feedback features prove addictive for many users. In the internet context the social is neither a reference to the social question, nor a hidden reminder of socialism as a political program. The social is precisely what it pretends to be: a calculated opportunity in times of distributed communication. In the end the social turns out to be a graph, a more or less random collection of contacts on your screen that blabber on and on - until you intervene and put your own statement out there.

Thanks to Facebook's simplicity the online experience is deeply human: the aim is the Other, not information. Ideally, the Other is online, right now. Communication works best if it is $24 / 7$, global, mobile, fast and short. Most appreciated is instantaneous exchange with befriended users at chat-mode speed. This is social media at its best. We are invited to 'burp out the thought you have right now - regardless of its quality, regardless of how it connects to your other thoughts'.13 Social presence of young people is the default here (according to the scholarly literature). We create a social sculpture, and then, as we do with most conceptual and participatory artworks, abandon it, ready to be trashed by anonymous cleaners. This is most like the faith of all social media: it will be remembered as an individual experience of online community in the post-9/11 decade. And happily forgotten as the next distraction consumes our perpetual present.

It is said that social media have grown out of virtual communities (as described by Howard Rheingold in his 1993 book of that title) but who cares really about the larger historical picture here? Many doubt if Facebook and Twitter, in their current manifestations as platforms for the millions, are still generating authentic online community experiences. What counts are the trending topics, the next platform and the latest apps. Silicon Valley historians will one day explain the rise of 'social networking sites' out of the remains of the dotcom crisis when a handful of survivors from the margins of the e-commerce boom 'n' bust reconfigured viable concepts of the Web 1.o era, stressing the empowerment of the user as content producer. The secret of Web 2.0, which kicked off in 2003, is the combination of (free) uploads of digital material with the 
ability to comment on other people's efforts. Interactivity always consists of these two components: action and reaction. Chris Cree defines social media as 'communication formats publishing user generated content that allow some level of user interaction', ${ }^{14}$ a problematic definition that could already include most of the early computer culture. It is not enough to limit social media to uploading and self-promotion. Social media are usually misunderstood if they are merely used as one-to-many marketing channels. It is the personal one-onone feedback and small-scale viral distribution elements that cannot be left out.

As Andrew Keen indicates in Digital Vertigo the social in social media is first and foremost an empty container, with the internet 'becoming the connective tissue of twenty-first century life' as the example hollow phrase. According to Keen, the social is becoming a tidal wave that is flattening everything in its path. Keen warns that we will end up in an antisocial future, characterised by the 'loneliness of the isolated man in the connected crowd'. ${ }^{15}$ Confined inside the software cages of Facebook, Google and their clones, users are encouraged to reduce their social life to 'sharing' information. The selfmediating citizen constantly broadcasts his or her state of being to an amorph, numb group of 'friends'. Keen is part of a growing number of (mainly) US critics who warn us of the side effects of extensive social media use. From Sherry Turkle's rant on loneliness, Nicholas Carr's warnings for the loss of brainpower and the lack of concentration, Evgene Morozov's critique of the utopian NGO world, to Jaron Lanier's concern over the loss of creativity, these commentators are united by their avoidance of a positive definition of the social. The problem here is the disruptive nature of the social, which returns as a revolt with an unknown, and often unwanted, agenda: vague, populist, radical-Islamist, driven by good for nothing memes.

The Other as opportunity, channel or obstacle? You choose. Never has it been so easy to 'auto-quantify' one's personal surroundings. We follow our blog statistics, the number of tweets, following and followers on Twitter, check out the friends of friends on Facebook or go on eBay to purchase a few hundred 'friends' who will then 'like' your latest uploaded pictures and 


\title{
start a buzz about your latest outfit. Listen to how Dave Winer sees the future of news:
}

\author{
Start a river, aggregating the feeds of the bloggers you most \\ admire, and the other news sources they read. Share your \\ sources with your readers, understanding that almost no \\ one is purely a source or purely a reader. Connect everyone \\ that's important to you, as fast as you can, as automatically \\ as possible, and put the pedal to the metal and take your \\ foot off the brake. ${ }^{16}$
}

\author{
This is how programmers these days glue everything loosely \\ together with code. Connect persons to data objects to per- \\ sons, that's the social today.
}

\section{Notes}

C. Chesher, 'How computer networks became social' in C. Chesher, K. Crawford, A. Dunn and S. Shaner, Internet Transformations: Language, Technology, Media and Power (forthcoming, 2015). J. Baudrillard, 'The Masses: Implosion of the Social in the Media', New Literary History 16, no. 3, On Writing Histories of Literature (Spring, 1985): 577-89, 577. All quotes from M. Hardt and A. Negri, Declaration (New York: Argo-Navis, 2012), 18-21.

4 Ibid., 35 .

5 See the exchange 'The $\$ 100$ bn Facebook question: Will capitalism survive 'value abundance'?' on the nettime list, early March 2012. Brian Holmes writes there in different postings: 'What I have found very limiting in the discourse around socalled web 2.o is the use of Marx's notion of exploitation in the strict sense, where your labor power is alienated into the production of a commodity and you get an exchange value in return.'; 'For years I have been dismayed by a very common refusal to think. The dismaying part is that it's based on the work of European history's greatest political philosopher, Karl Marx. It consists in the assertion that social media exploits you, that play is labor, and that Facebook is the new Ford Motor Co.'; 'The "apparatus of capture”, introduced by Deleuze and Guattari and developed into a veritable political economy by the Italian Autonomists and the Multitudes group in Paris, does something very much like that, though without using the concept of exploitation.'; 'Social media do not exploit you the way a boss does. It emphatically_does_sell statistics about the ways you and your friends and correspondents make use of your human faculties and desires, to nasty corporations that do attempt to capture your attention, condition your behavior and separate you from your money. In that sense, it does try to control you and you do create value for it. Yet that is not all that happens. Because you too do something with it, something of your own. The dismaying thing in the theories of playbour, etc, is that they refuse to recognise that all of us, in addition to being exploited and controlled, are overflowing sources of potentially autonomous productive energy. The refusal to think about this - a refusal which mostly circulates on the 
left, unfortunately - leaves that autonomous potential unexplored and partially unrealised.'

6 E. Illouz, Cold Intimacies: The Making of Emotional Capitalism (Cambridge: Polity Press, 2007).

7 Private email correspondance with the author, 5 March 2012.

8 A. Benschop, Virtual Communities, http://www.sociosite.org/network.php.

9 See R. Pfaller, Ästhetik der Interpassivität (Hamburg: Plilo Fine Arts, 2008) and G. van Oenen, Nu even niet! Over de interpassieve samenleving (Amsterdam: van Gennep, 2011).

10 See A. Ronell, The Telephone Book (Lincoln: University of Nebraska Press, 1989).

11 Baudrillard, 582.

12 Standard phrase from Professor Professor, a Bavarian character who speaks English with a heavy German accent in the BBC animation series The Secret Show (2006-07).

13 A. Giridharadas, 'A new, noisier way of writing', New York Times, 24 February $2012<$ http://www.nytimes.com/2012/02/25/us/25iht-currents25.html?_r=1>.

14 See $<$ http://successcreeations.com $/ 438 /$ definition-of-social-media/\#ixzz1nJmIQlic $>$.

15 A. Keen, Digital Vertigo (New York: St Martin's Press, 2012), 13.

16 D. Winer, 'What news must do', Scripting.com, 24 February $2012<$ http://scripting. com/stories/2012/02/24/whatNewsMustDo.html>. 